\title{
3 Research Square \\ Investigation of cerebrospinal fluid electrolytes and acid-base expressions in Asian adults
}

\section{Huang-Ping Yu}

Taoyuan Chang Gung Memorial Hospital

\section{Chia-Chih Liao}

Taoyuan Chang Gung Memorial Hospital

Jiun-Ting Yeh

Taoyuan Chang Gung Memorial Hospital

\section{Allen Li}

Taoyuan Chang Gung Memorial Hospital

Fu Chao Liu ( $\square$ ana5189@adm.cgmh.org.tw )

Taoyuan Chang Gung Memorial Hospital https://orcid.org/0000-0003-1712-4053

\section{Research article}

Keywords: Cerebrospinal fluid, Electrolyte, Acid-base

Posted Date: July 30th, 2019

DOI: https://doi.org/10.21203/rs.2.12160/v1

License: (c) (1) This work is licensed under a Creative Commons Attribution 4.0 International License. Read Full License 


\section{Abstract}

Background: Analysis of cerebrospinal fluid (CSF) parameters helps clinicians identify patients with central nervous system (CNS) disease. In previous literature, reference values for CSF may be based on patients who were not truly healthy, other species, or outdated information. In the present study, we performed lumbar puncture in patients requiring spinal anesthesia by a reasonable indication to evaluate CSF parameters in healthy adults. Methods: All patients between the ages of 20 and 70 years scheduled for elective orthopedic or urologic surgery requiring spinal anesthesia were enrolled in this study. We measured electrolytes and gas tension analysis in CSF and whole blood samples in adult humans. Results: A total of 28 patients were included with an average age of 44.2 years. The pH of blood and CSF were both neutral, but it was slightly lower in blood. The concentration of $\mathrm{Na}+$ in blood was slightly lower compared with that in CSF. There were significantly higher levels of $\mathrm{K}+$ and $\mathrm{Ca} 2+$ in the blood compared with CSF. Significantly lower levels of $\mathrm{Cl}$ - and $\mathrm{Mg} 2+$ in the blood were observed compared with CSF. The glucose level of CSF was about half of that in blood. Conclusions: We provided updated reference values for various solutes in blood and CSF in adults. Although normal CSF constituents are quite similar to that of blood, there is still a small difference in normal values between them. Analysis of CSF parameters and relevant paired blood samples is highly informative, helping clinicians diagnose a variety of CNS diseases. Trial registration: This present study was approved by the Institutional Review Board of Chang Gung Medical Foundation, Taiwan (approval number: 201600122A3), and is registered under Clinical Trials Registry (ClinicalTrials.gov Identifier: NCT03725709).

\section{Background}

Cerebrospinal fluid (CSF) is regarded as the transcellular fluid produced by the choroid plexus of the brain ventricles. It fills the ventricles and the subarachnoid space, and surrounds the brain and the spinal cord. The total volume of CSF is about 140 to $270 \mathrm{ml}$ in the adult. Since the daily production of CSF is 600$700 \mathrm{ml}$ per day, its turnover rate is about 3 to 5 times per day.

Analysis of CSF parameters helps clinicians in identifying and treating patients with central nervous system (CNS) disease due to the unique location of CSF and its close interaction with the brain parenchyma [1]. Although the respective electrolyte composition in human blood and CSF is quite similar, there is still a small difference between them under normal condition, which indicates that CSF is produced by active transport but not passive ultrafiltration [2,3]. Many CNS disorders that may result from altered enzymatic activity or neuronal abnormality lead to ionic imbalance in CSF, including Alzheimer's disease [4], neuromyelitis optica [5],traumatic brain injury [6],and seizure [7].

Although establishing accurate reference values for CSF electrolytes in adult humans are essential, it is still unethical to evaluate healthy adults with lumbar puncture, which is commonly used for the collection of CSF, solely for the purpose of establishing normal reference values since this is a painful and potentially harmful procedure. Therefore, in previous literature, reference values for CSF may be based on patients who were not truly healthy, other species, or outdated information [8].The objective of the present 
study was to determine clinically reference ranges for CSF and evaluate the difference between the composition in CSF and blood of adult humans. In our study, we sought to a reasonable indication for lumbar puncture in patients requiring spinal anesthesia to collect CSF samples for profile analysis.

\section{Methods}

This study was conducted according to the Declaration of Helsinki and approved by the Institutional Review Board of Chang Gung Memorial Hospital (IRB: 201600122A3). All patients were informed about the procedures and provided written informed consent to participate in the study. All the procedures and methods during the study were carried out in accordance with the approved guidelines

\section{Patients}

All patients with American Society of Anesthesiologists physical status I or II between the ages of 20 and 70 years scheduled for elective orthopedic or urologic surgery requiring spinal anesthesia were enrolled in this study. Patients were excluded if they had severe cardiovascular dysfunction, diabetes mellitus, the presence of CNS infection, a history of neurodegenerative disorders, meningitis or sepsis, a traumatic lumbar puncture, or there was a contraindication for regional anesthesia.

\section{Study Protocol}

When patients arrived in the operating room, standard monitorings including noninvasive arterial blood pressure, electrocardiography, and pulse oximetry were applied immediately and intravenous normal saline (500 1000 ml) was administered. All patients received spinal anesthesia through a midline approach at the L3-4 or L4-5 interspace with a 25-gauge Quincke-type needle by routine procedures.

em>To determine the values of the studied parameters, a CSF sample of $1 \mathrm{~mL}$ was obtained through the spinal needle before a single dose of 12.5 to $15 \mathrm{mg}$ of $0.5 \%$ isobaric bupivacaine (about 2.5 to $3 \mathrm{ml}$ ) was administered by the anesthesiologist for regional anesthesia. A whole blood sample of $2.5 \mathrm{ml}$ was obtained by arterial puncture from the dorsalis pedis or femoral artery before operation. The CSF and whole blood samples were both collected by commercial arterial blood collection syringes with a dry heparin preparation (Becton Dickinson, United Kingdom). Then electrolytes and gas tension analysis of CSF and whole blood samples were performed using a StatProfile ${ }^{\circledR}$ Critical Care Xpress (CCX) Analyzer (Nova Biomedical, Waltham, MA, USA).

\section{Statistical Analysis}

Calculation and data analyses were conducted with SPSS version 17.0 (SPSS Statistics for Windows; SPSS Inc, Chicago, IL). Categorical data were reported as numbers and percentages. Continuous data were reported as mean \pm standard deviation or mean (95\% confidence interval [CI]), and tested for 
normality using the Kolmogorov-Smirnov test. Parametric data were analyzed by using the paired t-test. Nonparametric data were analyzed with the Wilcoxon signed-rank test. Differences were considered statistically significant at $p<0.05$.

\section{Results}

Twenty-eight CSF and whole blood samples were obtained in this study. Their demographic data is presented in Table 1. There were $42.9 \%$ male and $57.1 \%$ female. The average age was 44.2 years and the range was 21 to 69 years. The percentiles for the age categories are shown in Figure 1. More samples were collected from the group of 51 to 60 years old than from other age groups.

\section{Gas tension analysis}

The results of gas tension analysis in blood and CSF are shown in Table 2. The pH of blood and CSF were both neutral, but the $\mathrm{pH}$ of blood was slightly lower than that of $\operatorname{CSF}(7.41[7.39,7.42]$ vs. $7.43[7.43$, 7.45]). The lower $\mathrm{pH}$ of blood is attributed to its higher $\mathrm{PCO}_{2}(35.79$ [33.67, 37.90] vs. 33.59 [32.00, 35.18] $\mathrm{mmHg})$, reflecting a decreased bicarbonate buffering capacity $(22.44[21.54,23.33]$ vs. 22.72 [21.99, 23.45] $\mathrm{mmHg}$ ) compared with CSF.

\section{Electrolyte and glucose analysis}

Electrolyte and glucose levels in blood and CSF are presented in Table 3. The concentration of $\mathrm{Na}^{+}$in blood was slightly lower compared with that in $\operatorname{CSF}(137.24$ [136.05, 138.43] vs. $138.34[137.18,139.50]$ $\mathrm{mEq} / \mathrm{L})$. There were significantly higher levels of $\mathrm{K}^{+}$and $\mathrm{Ca}^{2+}$ in the blood compared with CSF (3.71 [3.59, $3.83]$ vs. $2.75[2.72,2.79] ; 1.15[1.12,1.17]$ vs. $0.98[0.97,1.00] \mathrm{mEq} / \mathrm{L})$. Significantly lower levels of $\mathrm{Cl}^{-}$ and $\mathrm{Mg}^{2+}$ in the blood were observed compared with CSF $(109.51[108.59,110.44]$ vs. 122.10 [121.33, $122.87] ; 0.54[0.50,0.58]$ vs. $0.78[0.76,0.80] \mathrm{mEq} / \mathrm{L})$. The glucose level was markedly reduced in the CSF, which was about only half of that in blood $(56.52[53.96,59.08]$ vs. $108.56[104.88,138.15] \mathrm{mg} / \mathrm{dL})$.

\section{Discussion}

The CSF has many important physiological functions due to its special location and close interaction in the brain parenchyma. The accurate interpretation of CSF parameters is invaluable as a diagnostic tool in the evaluation of many CNS diseases. In the present study, we analyzed gas tension and electrolyte parameters of CSF in adult humans to establish updated reference values and have shown a difference of electrolyte levels between CSF and blood in adult humans.

Of its important functions, the CSF regulates the distribution of substances or nutrients in different areas of the brain. It may also act as a drainage pathway for the removal of metabolic waste products from brain cells or synapses [3]. The CSF is mainly produced by the choroid plexus, which is a branched 
structure made up of microvilli, each of which is composed of an epithelial monolayer surrounding a core of connective tissue and blood capillaries. Maintenance the $\mathrm{pH}$ in the CNS within a narrow range near 7.4 is an important mechanism. Neuronal function in CNS is highly susceptible to small acid-base changes. The blood brain barrier (BBB) provides a stable environment for neural function in CNS. The changes of CSF pH are associated with the function of BBB. It is relatively easily permeable to $\mathrm{CO}_{2}$, but impermeable to hydrogen and HCO3-ions. Noticeably, the central chemoreceptors in the medulla rapidly control respiration in response to the changes in CSF pH. In our study, the pH of blood and CSF were both near neutral, and the $\mathrm{pH}$ of CSF was slightly alkaline than that of blood. No significant differences in the $\mathrm{pCO}_{2}$ level were observed between the 2 groups. The lower $\mathrm{pH}$ of blood is attributed to a decreased bicarbonate buffering capacity compared with CSF.

The concentrations of various ions in the CSF are carefully regulated. Although the composition of main ions between CSF and blood determined in different animals are similar, they are certainly not the same [8]. A similar profile of main ion concentrations are also found in the human CSF presented in our study. Specifically, the concentrations of $\mathrm{Na}^{+}$is quite close between the blood and CSF, and the concentrations of $\mathrm{K}^{+}$and $\mathrm{Ca}^{2+}$ are lower in the CSF, whereas the $\mathrm{Cl}^{-}$concentration is greater in the CSF. The apical membrane of the choroid plexus facing the ventricle is the actual site of CSF production. The BBB keeps the ionic composition optimal for normal synaptic signalling function by a combination of specific transporters and ion channels. The driving force for secretion of CSF into the choroid plexus is unidirectional influx by ion transporters and channels that are distributed on the blood (basolateral) and CSF (apical) sides of the epithelial layer of choroid plexus [9]. Important molecular components of monovalent ions cross the CSF side of the choroid plexus include $\mathrm{Na}^{+} / \mathrm{K}^{+}$ATPase, $\mathrm{Na}^{+} / \mathrm{K}^{+} / 2 \mathrm{Cl}^{-}$cotransporter, and channels for the secretion of $\mathrm{K}^{+}$and $\mathrm{HCO}_{3}{ }^{-}$. The $\mathrm{Na}^{+} / \mathrm{K}^{+}$ATPase has important functions as pumping $\mathrm{Na}^{+}$into CSF and the process of CSF production. It drives $3 \mathrm{Na}^{+}$in exchange for $2 \mathrm{~K}^{+}$ions via energy produced by ATP hydrolysis that creates a gradient to carry $\mathrm{Na}^{+}$ions out of the choroid plexus cells and excess $\mathrm{K}^{+}$ions from the CSF. A Na ${ }^{+} / \mathrm{K}^{+} / 2 \mathrm{Cl}^{-}$co-transporter removes all the relevant ions out of the choroid plexus cells. The net effect of the transport of these ions is the unidirectional influx of $\mathrm{NaCl}$ and $\mathrm{NaHCO}_{3}$ into the cerebral ventricle accompanied by driving water movement from the bloodstream into the cerebral ventricle to form $\operatorname{CSF}[2,10]$.

The increasing studies revealed that brain $\mathrm{Ca}^{2+}$ controls the activity of ion channels and neurotransmitter release [11]. $\mathrm{Mg}^{2+}$ and $\mathrm{Ca}^{2+}$ in serum and CSF may modulate seizure activity [12]. Magnesium can inhibit $\mathrm{N}$-methyl-D-aspartate (NMDA) receptors, thus increasing anti-nociceptive and anesthetic effects of analgesics or anesthetics [13]. Administration of magnesium sulfate has neuroprotective effects in acute brain injury [14], and a recent study suggested that CSF $\mathrm{Mg}^{2+}$ concentration can be used as a surrogate marker of brain bioavailability and peripherally administered magnesium sulphate did not increase CSF the $\mathrm{Mg}^{2+}$ concentration in CSF [15]. However, the mechanisms affecting CSF $\mathrm{Mg}^{2+}$ concentration are not fully understood. Some studies showed that CSF $\mathrm{Mg}^{2+}$ concentration seemed not to be influenced by increased serum $\mathrm{Mg}^{2+}$ concentration in healthy or intracranial hypertension patients $[16,17]$. The balance 
of CSF $\mathrm{Mg}^{2+}$ ions is primarily controlled by active transport through a specific ion channel [18], and maintained at a concentration greater than that in blood as presented in our study.

Glucose is a vital metabolic energy source for the mammalian brain, and a continuous supply of glucose is essential to maintain a normal cerebral function. Glucose from blood enters the extracellular space of the brain via the GLUT family of transporters, mainly GLUT-1 and -3 , distributed on the endothelial cells of the BBB and in astrocytes [19]. In human adults, the general range for CSF glucose is about half to two thirds of that for blood glucose. In our study, the CSF/blood glucose ratio is 0.52 . This ratio may decrease with elevated blood glucose levels [20]. Patients with CNS infections such as bacterial or fungal usually cause low CSF/blood glucose ratio, but viral infection may have normal CSF glucose levels. Furthermore, there is not a specific pathologic process that directly results in high CSF glucose levels. Elevated blood sugar levels may lead to higher CSF glucose levels as diabetic patients because the sugar level in the blood is usually directly proportional to that in the CSF [21].

\section{Conclusions}

Although normal CSF constituents are quite similar to that of blood, there is still a small difference in normal values between them. Many CNS disorders may be reflected by altered CSF characteristics. Analysis of CSF parameters and relevant paired blood samples is highly informative, helping clinicians diagnose a variety of CNS diseases.

\section{List Of Abbreviations}

CSF: cerebrospinal fluid

CNS: central nervous system

BBB: blood brain barrier

NMDA: N-methyl-D-aspartate

\section{Declarations}

\section{Ethics approval and consent to participate:}

This study was approved by the Institutional Review Board of Chang Gung Medical Foundation in Taiwan (IRB: 201600122A3). All patients were informed about the procedures and provided written informed consent to participate in the study. All the procedures and methods during the study were carried out in accordance with the approved guidelines 


\section{Consent for publication:}

Not applicable

\section{Availability of data and material:}

The datasets used during the current study are available from the corresponding author on reasonable request.

\section{Competing interests:}

The authors declare that they have no competing interests

\section{Funding:}

This work was supported in part by grants from the Ministry of Science and Technology (MOST 1052314-B-182A-137-MY3) and Chang Gung Memorial Hospital (CMRPG3F1011-3). The funders had no role in study design, data collection and analysis, decision to publish, or preparation of the manuscript

\section{Authors' contributions:}

HPY and CCL: Author is responsible for search and review of the relevant literatures, analyzing the data, and writing the article.

JTY and AL: Author is responsible for assistant in literature search, help to collect data.

FCL: Correspondence is responsible for research design, drafting of the work or revising it critically for important intellectual content; and final approval of the version to be published

All authors have read and approved the final manuscript and agree with its submission to BMC Anesthesiology.

\section{Acknowledgements:}

none 


\section{References}

1. Deisenhammer F, Bartos A, Egg R,Gilhus NE, Giovannoni G, Rauer S, et al. Guidelines on routine cerebrospinal fluid analysis. Report from an EFNS task force. Eur J Neurol. 2006; 13: 913-922.

2. Speake T, Whitwell C, Kajita H, Majid A, Brown PD. Mechanisms of CSF secretion by the choroid plexus. Microsc Res Tech. 2001; 52: 49-59.

3. Brown PD, Davies SL, Speake T,Millar ID. Molecular mechanisms of cerebrospinal fluid production. 2004; 129: 957-970.

4. Hattori N, Kitagawa K, Higashida T, Yagyu K, Shimohama S, Wataya T, et al. Cl-ATPase and $\mathrm{Na}+/ \mathrm{K}(+)-A T P a s e$ activities in Alzheimer's disease brains. Neurosci Lett. 1998; 254: 141-144.

5. Akaishi T, Takahashi T, Nakashima I. Chloride imbalance between serum and CSF in the acute phase of neuromyelitis optica. J Neuroimmunol. 2018; 315: 45-49.

6. Saw MM, Chamberlain J, Barr M, Morgan MP, Burnett JR, Ho KM. Differential disruption of bloodbrain barrier in severe traumatic brain injury. Neurocrit Care. 2014; 20: 209-216.

7. Hallak M, Berman RF, Irtenkauf SM, Evans MI, Cotton DB. Peripheral magnesium sulfate enters the brain and increases the threshold for hippocampal seizures in rats. Am J Obstet Gynecol.1992;167: 1605-1

8. Davson H, Segal MB. Physiology of the CSF and Blood-Brain Barriers. Boca Raton, FL: CRC Press $1996,1832$.

9. Wright BL, Lai JT, Sinclair AJ. Cerebrospinal fluid and lumbar puncture: a practical review. J Neurol. 2012; 259: 1530-1545.

10. Redzic ZB, Segal MB. The structure of the choroid plexus and the physiology of the choroid plexus epithelium. Adv Drug Deliv Rev.2004; 56: 1695-1716.

11. Apostol A, Apostol R, Ali E, Choi A, Ehsuni N, Hu B, et al. Cerebral spinal fluid and serum ionized magnesium and calcium levels in preeclamptic women during administration of magnesium sulfate. Fertil Steril.2010; 94: 276-282.

12. Woolf CJ, Thompson SW. The induction and maintenance of central sensitization is dependent on Nmethyl-D-aspartic acid receptor activation; implications for the treatment of post-injury pain hypersensitivity states. Pain. 1991; 44: 293-299.

13. Lee DH, Kwon IC. Magnesium sulphate has beneficial effects as an adjuvant during general anaesthesia for Caesarean section. Br J Anaesth. 2009; 10; 861-866.

14. Veyna RS, Seyfried D, Burke DG, Zimmerman C, Mlynarek M, Nichols V, et al. Magnesium sulfate therapy after aneurysmal subarachnoid J Neurosurg.2002; 96; 510-514.

15. McKee JA, Brewer RP, Macy GE,Phillips-Bute B, Campbell KA, Borel CO, et al. Analysis of the brain bioavailability of peripherally administered magnesium sulfate: a study in humans with acute brain injury undergoing prolonged induced hypermagn Crit Care Med. 2005; 33: 661-666.

16. Brewer RP, Parra A, Borel CO, Hopkins MB, Reynolds JD. Intravenous magnesium sulfate does not increase ventricular CSF ionized magnesium concentration of patients with intracranial 
hypertension. Clin Neuropharmacol.2001;24: 341-345.

17. Mercieri M, De Blasi RA, Palmisani S, Forte S, Cardelli P, Romano R, et al. Changes in cerebrospinal fluid magnesium levels in patients undergoing spinal anaesthesia for hip arthroplasty: does intravenous infusion of magnesium sulphate make any difference? A prospective, randomized, controlled study. Br J Anaesth. 2012; 109: 208-215.

18. McKee JA, Brewer RP, Macy GE, Borel CO, Reynolds JD, Warner DS. Magnesium neuroprotection is limited in humans with acute brain injury. Neurocrit Care. 2005; 2: 342-351.

19. Duelli R, Kuschinsky W. Brain glucose transporters: relationship to local energy demand. News Physiol Sci.2001; 16: 71-76.

20. Jerrard DA, Hanna JR, Schindelheim GL. Cerebrospinal J Emerg Med.2001; 21: 171-178.

21. Seehusen DA, Reeves MM, Fomin DA. Cerebrospinal fluid analysis. Am Fam Physician. 2003; 68: 1103-1108.

\section{Tables}

Table 1 Patient demographic characteristics

\begin{tabular}{ll}
\hline Variables & $\mathrm{n}=28$ \\
\hline Age (years) & $44.2 \pm 13.7$ \\
$\mathrm{M} / \mathrm{F}$ & $12(42.9) / 16(57.1)$ \\
Weight $(\mathrm{kg})$ & $61.8 \pm 10.6$ \\
Height $(\mathrm{cm})$ & $162.6 \pm 6.1$ \\
BMI $\left(\mathrm{kg} / \mathrm{m}^{2}\right)$ & $23.3 \pm 3.4$ \\
\hline
\end{tabular}

$\mathrm{M}=$ male; $\mathrm{F}$ = female.

Data are reported as mean \pm standard deviation or number (\%).

Table 2 Comparison between blood and CSF on gas tension variables

\begin{tabular}{|c|c|c|c|c|}
\hline & Blood & $\mathrm{CSF}$ & $p$ value & Ratio \\
\hline & $(n=28)$ & $(\mathrm{n}=28)$ & & (CSF/Blood) \\
\hline $\begin{array}{l}\mathrm{pH} \\
\mathrm{PCO}_{2}(\mathrm{mmHg})\end{array}$ & $\begin{array}{l}7.41(7.39,7.42) \\
35.79(33.67,37.90)\end{array}$ & $\begin{array}{l}7.43(7.43,7.45) \\
33.59(32.00,35.18)\end{array}$ & $\begin{array}{c}<0.0001 \\
0.1915\end{array}$ & $\begin{array}{l}1.0038 \\
0.9386\end{array}$ \\
\hline $\mathrm{HCO}_{3}{ }^{-}(\mathrm{mEq} / \mathrm{L})$ & $22.44(21.54,23.33)$ & $22.72(21.99,23.45)$ & 0.3718 & 1.0127 \\
\hline $\begin{array}{l}\mathrm{SBC}(\mathrm{mEq} / \mathrm{L}) \\
\mathrm{BE}(\mathrm{mEq} / \mathrm{L})\end{array}$ & $\begin{array}{l}23.24(22.66,23.67) \\
-1.33(-1.96,-0.70)\end{array}$ & $\begin{array}{l}24.18(23.72,24.63) \\
-0.32(-0.86,0.22)\end{array}$ & $\begin{array}{l}0.0015 \\
0.0051\end{array}$ & $\begin{array}{l}1.0402 \\
0.2417\end{array}$ \\
\hline $\mathrm{TCO}_{2}(\mathrm{mmol} / \mathrm{L})$ & $23.41(22.45,24.37)$ & $23.71(22.91,24.52)$ & 0.3646 & 1.0130 \\
\hline
\end{tabular}

SBC: standard bicarbonate; BE: base excess. 
Data are reported as mean $(95 \% \mathrm{CI})$.

Table 3 Comparison between blood and lumbar CSF on electrolyte variables

\begin{tabular}{|c|c|c|c|c|}
\hline & Blood & $\mathrm{CSF}$ & \multirow[t]{2}{*}{$p$ value } & Ratio \\
\hline & \multirow{4}{*}{$\begin{array}{l}(\mathrm{n}=\mathrm{L}) \\
12.24(10.64,13.84) \\
137.24(136.05, \\
138.43) \\
3.71(3.59,3.83)\end{array}$} & \multirow{4}{*}{$\begin{array}{l}(\mathrm{n}=28) \\
11.44(10.44,12.44) \\
138.34(137.18, \\
139.50) \\
2.75(2.72,2.79)\end{array}$} & & (CSF/Blood) \\
\hline$\overline{\mathrm{BUN}}(\mathrm{mg} / \mathrm{dl})$ & & & 0.0941 & 0.9346 \\
\hline $\mathrm{Na}^{+}(\mathrm{mEq} / \mathrm{L})$ & & & 0.0143 & 1.0080 \\
\hline $\mathrm{K}^{+}(\mathrm{mEq} / \mathrm{L})$ & & & \multirow{5}{*}{$\begin{array}{c}< \\
0.0001 \\
< \\
0.0001 \\
< \\
0.0001 \\
0.0002 \\
0.0031\end{array}$} & 0.7416 \\
\hline $\mathrm{Cl}^{-}(\mathrm{mEq} / \mathrm{L})$ & \multirow{2}{*}{$\begin{array}{l}109.51(108.59, \\
110.44) \\
1.15(1.12,1.17)\end{array}$} & \multirow{2}{*}{$\begin{array}{l}122.10(121.33, \\
122.87) \\
0.98(0.97,1.00)\end{array}$} & & 1.1150 \\
\hline $\mathrm{Ca}^{2+}(\mathrm{mEq} / \mathrm{L})$ & & & & 0.8591 \\
\hline $\mathrm{Mg}^{2+}(\mathrm{mEq} / \mathrm{L})$ & \multirow{4}{*}{$\begin{array}{l}0.54(0.50,0.58) \\
275.43(272.99, \\
277.87) \\
108.56(104.88, \\
138.15)\end{array}$} & \multirow{5}{*}{$\begin{array}{l}0.78(0.76,0.80) \\
272.92(271.07, \\
274.78) \\
56.52(53.96,59.08) \\
1.11(1.02,1.19)\end{array}$} & & 1.4408 \\
\hline Osm $(\mathrm{mOsm} / \mathrm{L})$ & & & & 0.9909 \\
\hline Glucose & & & \multirow{3}{*}{$\begin{array}{c}< \\
0.0001 \\
0.9873\end{array}$} & 0.5206 \\
\hline & & & & 0.9536 \\
\hline $\mathrm{Lac}(\mathrm{mmol} / \mathrm{L})$ & $1.16(0.83,1.49)$ & & & \\
\hline
\end{tabular}

Data are reported as mean (95\% CI).

Figures 


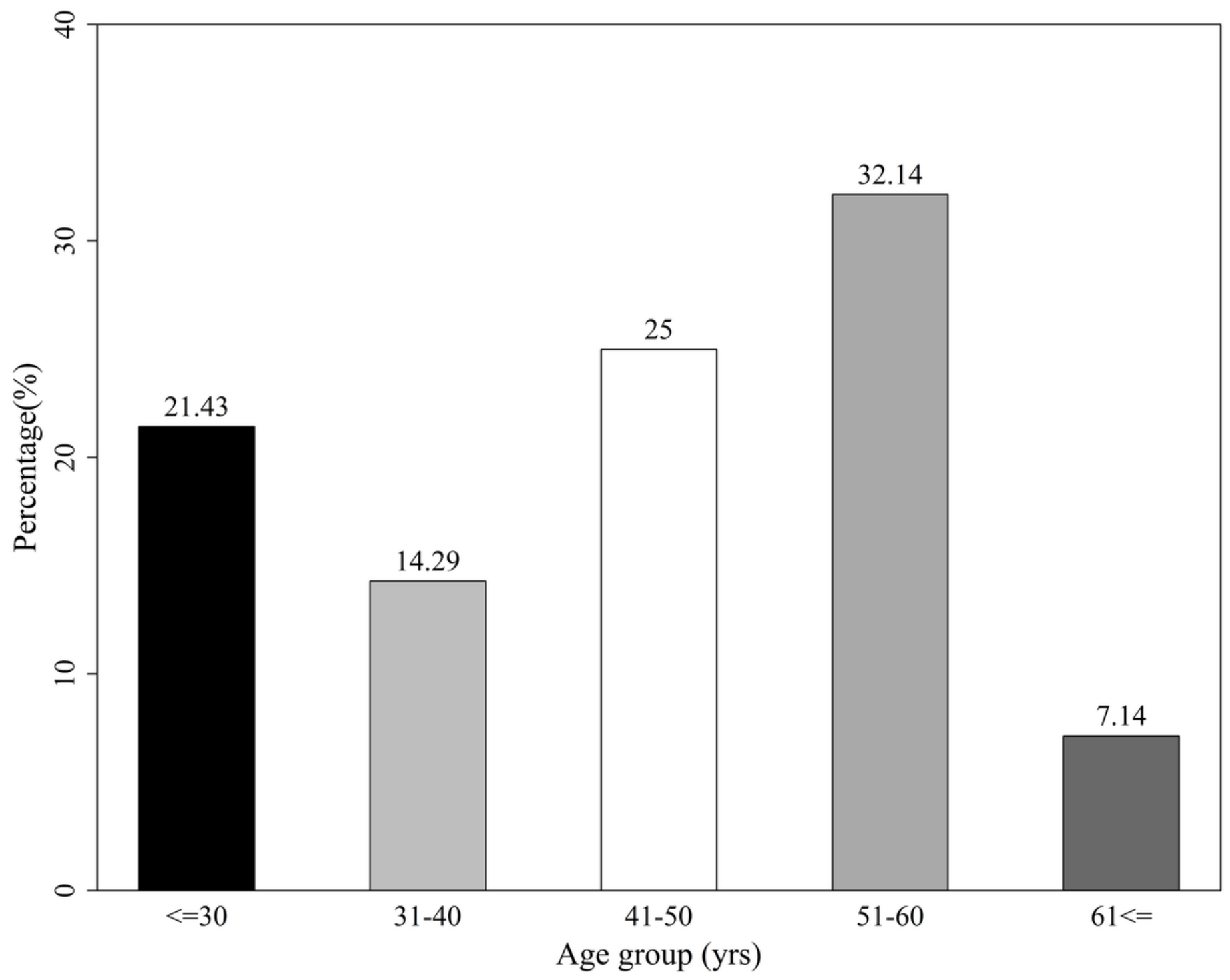

Figure 1

Percentiles in different age categories 